\title{
Aplikasi Metode Ground Penetrating Radar Terhadap Pola Retakan Di Bendungan Batu Tegi Lampung
}

\author{
Somantri Aji $\mathbf{P}^{1}$; Pulung Arya ${ }^{1^{*}}$; Mimin Iryanti ${ }^{1^{*}}$ \\ 1)Departemen Pendidikan Fisika, FPMIPA, Universitas Pendidikan Indonesia \\ Jl. Dr. Setiabudhi No. 229, Bandung dan 40154
}

Email :somantriajipratama@gmail.com,poel_pranantya@yahoo.com

\begin{abstract}
ABSTRAK
Munculnya retakan pada urugan bendungan Batu Tegi Lampung sangat mengganggu keselamatan diwilayah tersebut. Dalam hal ini perlunya dilakukan investivigasi terhadap retakan - retakan yang muncul dipermukaan urugan bendungan. Penelitian Ground Penetrating Radar (GPR) merupakan metode geofisika sebagai alat bantu untuk penelitian geologi bawah permukaan dangkal dan terperinci. Penetrasi kedalaman metode GPR ini sangat bergantung pada sifat listrik geologi bawah permukaan dengan prinsip kerja pengirim dan penerima pulsa gelombang, sehingga akan muncul struktur lapisan bawah permukaan karena terdapatnya anomali bawah permukaan pada radargram. Pengolahan serta interpretasi data georadar pada penelitian ini menggunakan software Reflexw. Sehingga hasil penelitian dari metode GPR ini menunjukan pola retakan yang muncul pada urugan bendungan Batu Tegi. Yang nantinya dapat dipergunakan untuk membantu perencanaan mengevaluasi desain, kontruksi pada urugan bendungan maupun perencanaan mitigasi.
\end{abstract}

Kata kunci: Ground Penetrating Radar (GPR), Radargram, Reflexw, Urugan

\begin{abstract}
Appered of fracture on earth dam Batu Tegi Lampung need concerned for a lot aspect in that area. In this case, we did investivigation about appered more fracture on surface earth dam. The Ground Penetrating Radar (GPR) survey is one of the geophysical method which is developed as a toll for a relatively shallow and detailed subsurface geological survey. The penetration depth of GPR method it depends on electric properties of subsurface with work principle transmitter and receiver wave pulse, it will show up on radargram image of subsurface because of the subsurface have an anomaly. Data processing with interpretation of data georadar in this investivigation using Reflexw software. The result from GPR method shows fracture pattern on earth dam Batu Tegi. From these results, the GPR method can very useful to help design evaluation plan, construction and mitigation plan also for earth dam.
\end{abstract}

Keywords: Ground Penetrating Radar (GPR), Radargram, Reflexw, Earth dam. 


\section{PENDAHULUAN}

Bendungan merupakan penahan air tampungan berupa timbunan urugan berbentuk bendung atau dam. Di Indonesia, kebanyakan bendungan merupakan urugan tanah homogen dan zonal sisanya ada pula bendungan urugan batu. Bendungan urugan dibangun dengan cara menimbun tanah, pasir dan kerikil dalam posisi tertentu untuk membatasi suatu lembah, dalam potongan melintang. Biasanya bendungan tipe urugan dibangun untuk menyangga sekaligus penahan air rembesan yang memperkuat Bendungan dalam menampung jumlah air didalamnya. Apabila rembesan air yang terjadi terlalu besar maka akan mengakibatkan terganggunya fungsional bendungan, rawan runtuh atau longsor.

Di Wilayah lampung terdapat 3 buah bendungan, yaitu bendungan Way Rarem, bendungan Tirta Shinta dan Bendungan Batu Tegi. Ketiga bendungan terdapat Pembangkit Listrik Tenaga Air (PLTA) yang digunakan untuk menyuplai listrik bagi penduduk sekitarnya. Salah satu yang memiliki dampak cukup besar adalah bendungan Batu Tegi, yang terletak di Kecamatan Talang Padang, Kabupaten Tanggamus, Provinsi Lampung. Selain salah satu bendungan terbesar di Indonesia sehingga daya tampung air pada bendungan Batu Tegi ini cukup besar, juga sebagai penyuplai air yang digunakan oleh puluhan ribu hektar areal persawahan yang dilewati oleh aliran dari bendungan Batu Tegi itu sendiri. Melihat kondisi dari Bendungan Batu Tegi yang memiliki peranan besar terhadap wilayah sekitarnya, pasti akan rawan terhadap bencana alam salah satunya yaitu bencana runtuhnya sebuah bendungan. Dimana bencana jika terjadi tidak hanya merusak fasilitas berbagai macam fasilitas dan juga dapat merenggut jiwa manusia.

Pada kasus Bendungan Batu Tegi terdapat retakan - retakan yang muncul pada permukaan urugan bendungan. Selain itu, masalah volume air dan terdapatnya galery didalam bendungan menjadi resiko terjadina bencana. Jika volume air dibendungan melebihi tinggi dari urugan dan banyak air yang masuk kedalam retakan permukaan urugan bendungan maka urugan menjadi tidak stabil. Begitu pula munculnya air di setiap dinding galery. Oleh karena itu untuk mencegah musibah yang dapat merugikan secara korban jiwa dan material, perlu diperhatikan stabilitas bendungan, perhitungan kestabilan terhadap geser, guling dan piping (angkat) (Mawardi 2004). Berdasarkan fenomena kejadian tersebut, untuk meneliti permasalahan retakan yang timbul di urugan tanah harus langsung terjun ke bendungan yang sebenarnya.

Penyelidikan dengan metode geofisika dapat membantu untuk mendapatkan gambaran awal dalam proses retakan pada urugan tanah dan juga kemudian dibandingkan dengan pengujian metode lain yang sudah digunakan.

Ground Penetrating Radar (GPR) memiliki cara kerja yang sama dengan radar konvensional dengan mengirim pulsa energi antara 40 sampai $4 \mathrm{GHz}$ ke dalam tanah oleh 
antena pemancar lalu mengenai suatu lapisan atau objek dengan suatu konstanta dielektrik berbeda selanjutnya pulsa akan dipantulkan kembali dan diterima oleh antena penerima, waktu dan besar pulsa direkam. Pemancaran dan pengembalian gelombang elektromagnet berlangsung cepat sekali yaitu dalam satuan waktu nannosecond (Allen, 1979).

Kedalaman penetrasi dengan metode georadar sangat bergantung sifat kelistrikan media yang diselidiki, seperti: konduktivitas listrik dan konstanta dielektrik. Kedua sifat listrik tersebut berkaitan erat dengan sifat fisik tanah atau batuan yang antara lain kadar air dan sifat kegaramannya. Khusus dalam pendeteksian material yang kadar besinya relatif tinggi, penetrasi GPR akan berkurang, sesuai dengan kadar besi yang terdapat pada material tersebut (Budiono, 1999). Di daerah penelitian, kemampuan penetrasi pada masing-masing lintasan disesuaikan dengan tujuan utama pendeteksian.
Data GPR yang diperoleh kemudian diproses lebih lanjut.

Survey GPR digunakan sebagai penginderaan bawah permukaan dangkal dan dapat digunakan secara efektif untuk menentukan geologi bawah permukaan dangkal jika data GPR diproses dan diinterpretasikan secara tepat.

\section{METODE PENELITIAN}

Penelitian ini data digunakan merupakan data sekunder yang diperoleh dari time Pusat Penelitian dan Pengembangan Sumber Daya Air (PUSAIR). Pengambilan data georadar dilakukan di 31 lintasan diarea surveu yang berukuran $30 \times 19$ m. 33 lintasan ini terdiri dari 15 lintasan frekuensi $1 \mathrm{GHz}, 7$ lintasan frekuensi $400 \mathrm{MHz}, 7$ Lintasan frekuensi $40 \mathrm{MHz}$ dan 4 lintasan yang panjang 30 meter memakai frekuensi $400 \mathrm{MHz}$. Pada gambar 1 terlihat lintasan ini dibuat persegi panjang melingkupi retakan yang muncul dipermukaan bendungan.

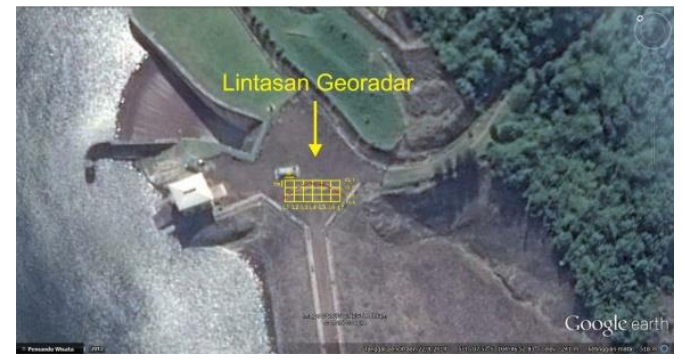

Gambar 1. Lintasan georadar pada permukaan bendungan Batu Tegi Sumber : http://earth.google.com

Pada penelitian ini, dilakukan beberapa langkah untuk mencapai tujuan penelitian. Data hasil akuisisi diproses secara terpadu dalam pengolahan data GPR menggunakan

program REFLEXW (Reflex for windows). Langkah pertama ialah data hasil penelitian diproses dengan memilih project data. Selanjutnya 
dilakukan tahapan $1 D$ filter (dewow) terhadap data pengukuran yang kurang baik. Koreksi data dilakukan untuk mendapatkan nilai rata - rata data terhadap titik tengah (central point), Static Correction dimaksudkan untuk melakukan normalisasi secara vertikal, sehingga nilai kedalaman menjadi akurat, memberikan Gain kepada data - data sesuai keperluan. Hal ini dimaksudkan agar data hasil pengukuran yang lemah akan dapat terlihat lebih jelas, $2 D$ Background Removal atau noise filtering yang mereduksi adanya noise - noise yang muncul sebagai garis - garis horizontal pada radargran dan 1D Filter (bandpass frequency) dilakukan untuk memfilter kembali data frekuensi agar sesuai keperluan.

Untuk lebih jelas dapat dilihat di gambar 2.

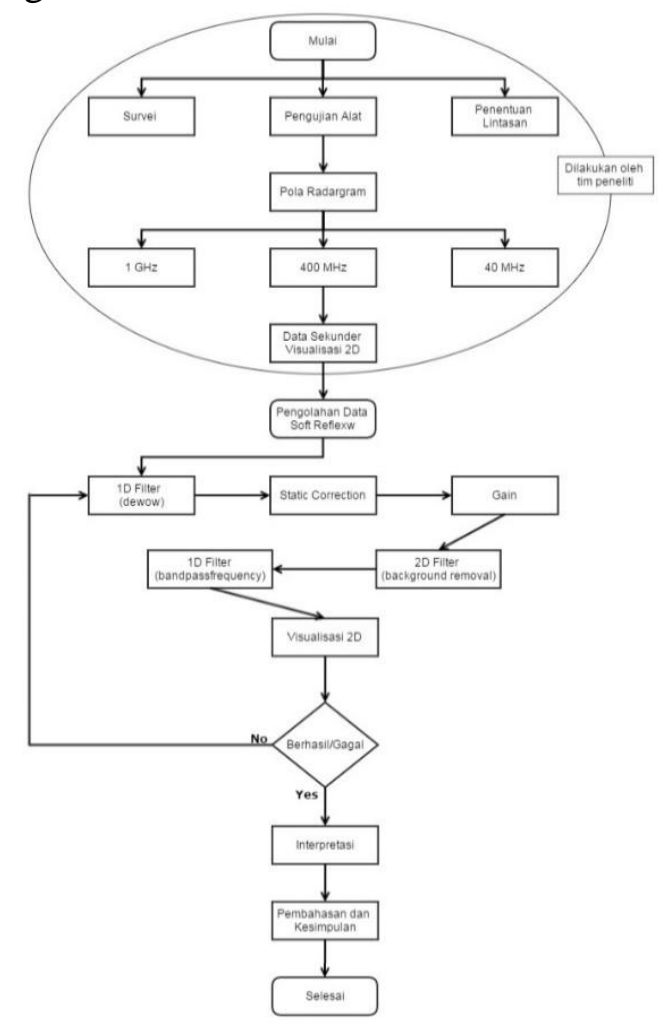

Gambar 2. Diagram Alur Metode Pengolahan Data

\section{HASIL DAN PEMBAHASAN}

Penelitian menggunakan metode ground penetrating radar didapatkan tiga puluh tiga lintasan pengukuran, diantaranya lima belas lintasan berupa tanda G1 hingga G15 adalah pengambilan data dari antena $1 \mathrm{GHz}$, tujuh lintasan berupa tanda L1 hingga L7 adalah pengambilan data dari antena $40 \mathrm{MHz}$, tujuh lintasan berupa tanda L1 hingga L7 adalah pengambilan data dari antena 400 $\mathrm{MHz}$, dan empat lintasan panjang CL1 hingga CL4 adalah 
pengambilan data antena $40 \mathrm{MHz}$. Untuk semua lintasan dapat dilihat pada gambar 3. Pada penelitian ini setiap lintasan memiliki panjang yang berbeda - beda dan pengambilan data dilakukan sepanjang permukaan yang mengalami retakan. Hal ini dimaksudkan dengan kondisi lapangan dan kebutuhan data yang diperlukan.

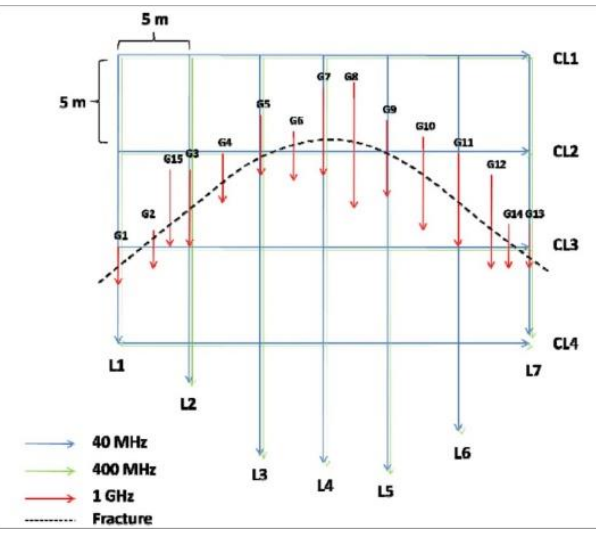

Gambar 3. Lintasan Pengukuran Georadar

Data hasil pengukuran georadar yang diambil sebanyak 33 (tiga puluh tiga) lintasan kemudian diolah menggunakan software REFLEXW dengan maksud agar dapat memberikan informasi mengenai pola retakan dibagian bendungan secara jelas. Melalui hasil proses analisis yang berupa radargram ini menjadi acuan untuk menentukan pola retakan serta kedalaman retakan disetiap lintasannya. Dibawah ini merupakan 3 jenis radargram dan penampang lintasan hasil pengolahan data menggunakan software REFLEXW, beserta pola retakan yang ditandai oleh garis warna hitam. Lintasan ini dipilih dan diolah karena melewati retakan yang muncul dipermukaan bendungan sehingga didapat kejelasan pola retakan serta kedalaman retakan tersebut.

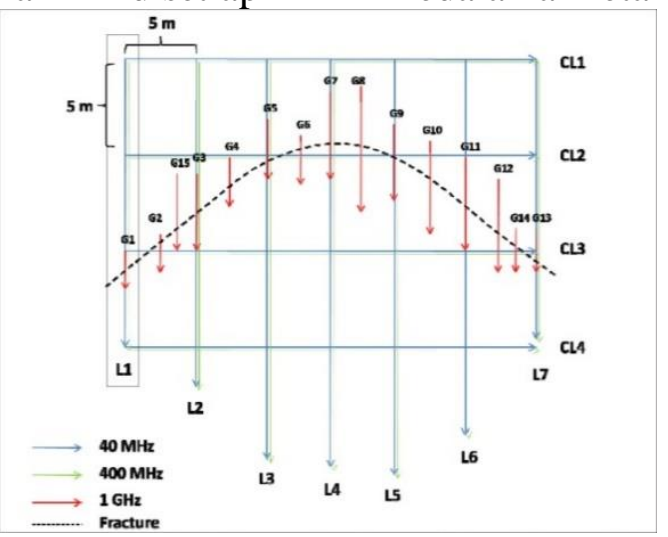

Gambar 4. Lintasan Pertama 


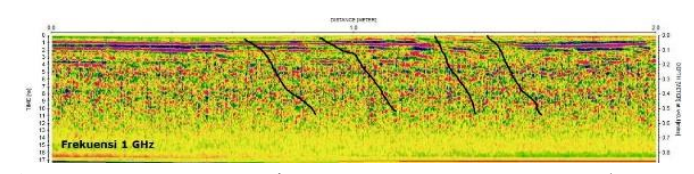

Gambar 5. Penampang Lintasan Pertama Frekuensi $1 \mathrm{GHz}$.

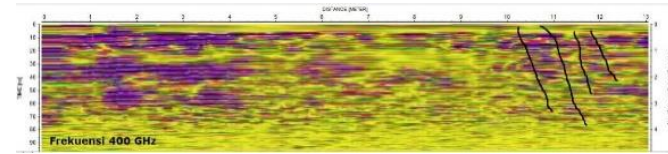

Gambar 6. Penampang Lintasan Pertama Frekuensi 400 MHz.

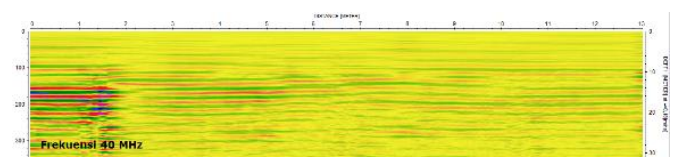

Gambar 7. Penampang Lintasan Pertama Frekuensi 40 MHz.

Pada gambar 4, lintasan pertama terlihat dari gambar lintasan pengukuran terdapat 3 jenis pengukuran yakni dengan antena 1 $\mathrm{GHz}, 400 \mathrm{MHz}$ dan $40 \mathrm{MHz}$. Untuk penampang lintasan pertama pada gambar 5, penampang frekuensi $1 \mathrm{GHz}$ yang memiliki panjang lintasan sepanjang 2 meter terlihat pola retakan yang mencapai kedalaman $\pm 0,5$ meter. Pada penggunaan frekuensi $1 \mathrm{GHz}$ memberikan penetrasi yang dangkal kurang lebih 1 meter tetapi resolusi yang didapat cukup tinggi. Pola yang diindikasi sebagai retakan ditandai dengan garis warna hitam.

Untuk mengetahui pola retakan yang berlanjut dari antena $1 \mathrm{Ghz}$ lebih dalam, dilakukan pengambilan data menggunakan antena $400 \mathrm{MHz}$ yang memiliki penetrasi kedalaman hingga 5 meter. Hasilnya pada gambar 6, pada frekuensi $400 \mathrm{MHz}$ terlihat retakan (ditandai dengan garis warna hitam) pada penampang lintasan permukaan 13 meter mencapai kedalaman \pm 4 meter, hanya saja resolusi yang didapat cukup rendah. Selanjutnya dilakukan pengukuran dengan frekuensi $40 \mathrm{MHz}$ yang memiliki penetrasi kedalaman hingga 30 meter, dari hasilnya pada gambar 7 pengolahan pola retakan pada frekuensi $40 \mathrm{MHz}$ tidak terlihat kelanjutan pola retakan dari antena $40 \mathrm{MHz}$ sebelumnya dan juga resolusi yang didapat sangat rendah.

Sehingga prediksi kedalaman retakan hanya sampai 4 meter sesuai dengan hasil pengolahan pada frekuensi antena $400 \mathrm{MHz}$.

Setelah pemrosesan lintasan sebanyak 33 lintasan selanjutnya diinterpretasi kembali dalam 3 dimensi yang ditunjukan pada gambar 8 dan gambar 9 . 


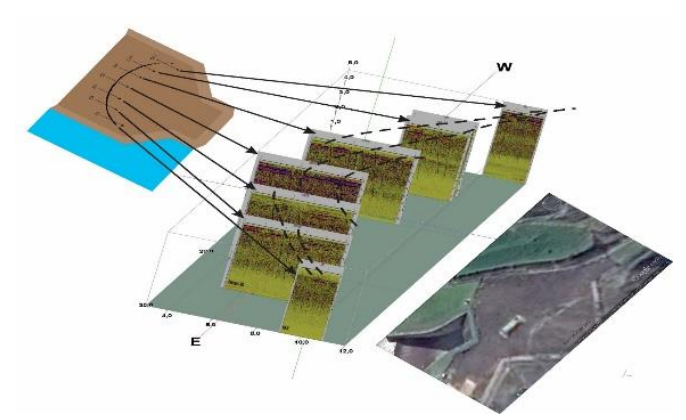

Gambar 8. Model 3D lintasan Utama $1 \mathrm{GHz}$

Hasil pemrosesan gambar 3D pada gambar 8 , terlihat 3 gambar yakni ilustrasi gambar pola lintasan pada bendungan Batu Tegi, gambar hasil pemrosesan 3D dari 7 lintasan georadar (frekuensi $1 \mathrm{GHz}$ ) dan hasil pencitraan satelit lokasi bendungan Batu Tegi. Dari hasil pencitraan satelit terlihat warna yang merupakan pola retakan yang telah tertutupi oleh semen sebelumnya. Dari pemrosesan 3D terlihat penggabungan antara interpretasi 2D setiap lintasan yang mengarah dari timur ke barat dan pola retakan pada permukaan atas bendungan (garis putus warna hitam).

Berdasarkan pemrosesan data diatas, dari 7 lintasan utama dengan panjang lintasan yang berbeda-beda tetapi spasi setiap lintasan 1 meter. Terlihat adanya kecocokan antara pola retakan yang muncul pada permukaan bendungan dengan hasil interpretasi dari georadar antenna frekuensi $1 \mathrm{GHz}$. Terlihat pola retakan disetiap lintasan didasarkan atas adanya kontras kecepatan pada setiap radargram, kontras kecepatan hasil pengambilan data pada masing masing lapisan menandakan adanya perubahan jenis lapisan dilihat dari kontras amplitudo. Karena kecepatan berbanding lurus dengan amplitude gelombang. Sehingga terlihat adanya kontras amplitude dilihat dari warna yang muncul pada setiap radargram lintasan.

Dari data radargram setiap lintasan menunjukan intensitas warna yang berbeda-beda, intesitas warna pada tampilan radargram merupakan pencitraan dari kuat lemahnya amplitudo tiap lintasan. Sehingga semakin kuat intensitas warna semakin kuat pula amplitudo yang muncul pada radargram, dan sebaliknya. Hal ini menunjukan adanya kontak setiap lapisan bendungan, karena bendungan sendiri dibentuk dari beberapa lapisan yang dipadatkan berkelanjutan dari dasar bendungan, badan bendungan hingga bagian atas permukaan bendungan (bendungan Batu Tegi). Dengan asumsi yang dipakai bahwa amplitudo kuat ditandai oleh dominan warna gelap (ungu-biru) dan amplitudo lemah ditandai oleh warna cerah (hijau-kuning). Maka berdasarkan referensi tersebut dapat diinterpretasi, bahwa terdapat jarak antara amplitudo kuat dan amplitudo lemah yang 
diindikasikan sebagai pola retakan sesuai dengan yang muncul dipermukaan atas bendungan Batu
Tegi. Hasil interpretasi 3D tidak lebih dari 1 meter karena pengaruh dari antena frekuensi $1 \mathrm{GHz}$.

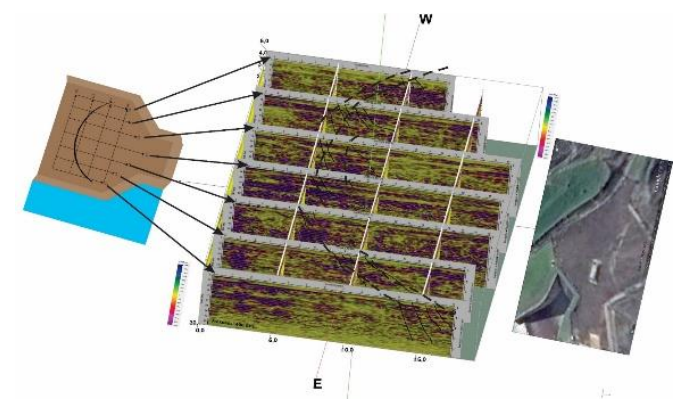

Gambar 9. Model 3D Lintasan gabungan $400 \mathrm{MHz}$

Hasil pemrosesan gambar 3D pada gambar 9, terlihat 3 gambar yakni ilustrasi gambar pola lintasan pada bendungan Batu Tegi, gambar hasil pemrosesan 3D dari 11 lintasan georadar (frekuensi $400 \mathrm{MHz}$ ) dan hasil pencitraan satelit lokasi bendungan Batu Tegi. Dari hasil pencitraan satelit terlihat warna yang merupakan pola retakan yang telah tertutupi oleh semen sebelumnya. Dari pemrosesan 3D terlihat penggabungan antara interpretasi 2D setiap lintasan yang mengarah dari timur ke barat dan pola retakan pada permukaan atas bendungan (garis putus warna hitam).

Berdasarkan pemrosesan data diatas, dari 11 lintasan (7 lintasan utama dan 4 lintasan memotong lintasan utama) dengan panjang lintasan yang berbeda-beda tetapi spasi setiap lintasan 1 meter. Terlihat adanya kecocokan antara pola retakan yang muncul pada permukaan bendungan dengan hasil interpretasi dari georadar antena frekuensi $400 \mathrm{MHz}$. Terlihat pola retakan disetiap lintasan didasarkan atas adanya kontras kecepatan pada setiap radargram, kontras kecepatan hasil pengambilan data pada masing masing lapisan menandakan adanya perubahan jenis lapisan dilihat dari kontras amplitudo. Karena kecepatan berbanding lurus dengan amplitude gelombang. Sehingga terlihat adanya kontras amplitudo dilihat dari warna yang muncul pada setiap radargram lintasan.

Dari data diatas merupakan kelanjutan dari frekuensi $1 \mathrm{GHz}$ yang memiliki kedalaman hanya sampai 1 meter sehingga dibantu oleh data frekeunsi $400 \mathrm{MHz}$ yang memiliki kedalaman mencapai 5 meter. Dalam hal ini, hasil interpretasi pola retakan sebagian besar merupakan kelanjutan dari antenna $1 \mathrm{GHz}$, tetapi kedalamannya memiliki variasi yang berbeda - beda. Kejadian ini bisa saja disebabkan karena pengaruh penurunan tidak seragam (differential settlement). Yang berakibat penurunan konsolidasi tanah dibawah timbunan sehingga menyebabkan 
melengkung atau turunnnya permukaan atas timbunan yang mengakibatkan retaknya pada permukaan bendungan Batu Tegi. Terlebih dari hasil pencitraan satelit dengan hasil interpretasi 3D terdapat kecocokan dari segi pola retakan (garis - garis warna hitam) yang muncul di permukaan bendungan Batu Tegi.

\section{SIMPULAN}

Berdasarkan pengukuran dan analisis data yang dilakukan di Bendungan Batu Tegi Lampung menggunakan Metode Ground Penetrating Radar, dapat disimpulkan sebagai berikut :

Terlihatnya retakan pada permukaan bendungan Batu Tegi Lampung menunjukan terdapat pola retakan di area pengukuran pada bendungan memiliki variasi kedalaman mulai dari 0,5 meter hingga kurang dari 4 meter dengan kemiringan tertentu. Dengan menggunakan tiga frekuensi yang berbeda yakni $1 \mathrm{GHz}, 40 \mathrm{MHz}$ dan $400 \mathrm{MHz}$ sangat membantu mengidentifikasi pola retakan hingga kedalaman kurang 4 meter pada badan bendungan. Pola retakan yang diinterpretasi disebabkan oleh penurunan tidak seragam (differential settlement). bisa mengakibatkan seepage atau erosi buluh yang terjadi pada badan bendungan. Air rembesan dari bendungan sedikit demi sedikit mengikis badan bendungan yang terdiri dari komponen urugan tanah homogen. Berdasarkan visualisasi radargram 3D maka kondisi pola retakan cenderung mengarah ke arah timur bendungan.

Berdasarkan penelitian yang telah dilakukan, maka rekomendasi yang diberikan untuk penelitian selanjutnya yaitu dilakukan akuisisi data georadar pada data $40 \mathrm{MHz}$ untuk mendapatkan hasil data pengukuran yang lebih optimal dan juga didukung oleh metode geofisika yang agar timbulnya anomali terhadap data yang dianalisis.

Pada kasus bendungan Batu Tegi, harus dilakukan pengecekan air pada bendungan agar tidak meluap pada badan bendungan. Hal ini bisa berakibat terkikisnya badan bendungan, selain itu pencegahan dapat dilakukan dengan cara menutup serta mengisi retakan yang muncul pada permukaan bendungan dengan perekat yang kuat.

\section{REFERENSI}

1. Annand, A.P. (2001). Ground Penetrating Radar Workshop Notes. Sensore and Software Inc. Canada.

2. Budiono, K. et al. (2010). Penafsiran Struktur Geologi Bawah Permukaan di Kawasan Semburan Lumpur Sidoarjo, Berdasarkan Penampang Ground Penetrating Radar (GPR). Jurnal Geologi Indonesia, Vol. 5 No. 3.

3. Deniyatno. (2011). Identifikasi Zona Bidang Gelincir Tanah Longsor Dengan Metode Georadar. Jurnal Aplikasi Fisika Volume 7 Nomor 2. Jurusan Fisika FMIPA. Universitas Haluoleo. Kendari, Sulawesi Tenggara.

4. Milson, J. (2003). Field Geophysics The Geologival Field Guide Series. 
Third Edition. Jhon Wiley \& Sons

Ltd.

5. Ramalis, T.R. (2001). Common

Textbook Gelombang dan Optik. Jurusan Pendidikan Fisika FPMIPA UPI. Bandung.

6. Telford, W.M., Geldart, L.P dan Sheriff, R.E. (1990). Applied Geophysics. Second Edition. Cambridge: Cambridge University Press.

7. Tipler P.A. : alih bahasa, Bambang Sogijono (2001). Fisika Untuk Sains dan Teknik (edisi ketiga). Erlangga . Jakarta 